\title{
RISK, INTERMEDIATE INPUT PRICES AND MISSING DEFLATION DURING THE GREAT RECESSION
}

\author{
Engin Kara \\ Ahmed Jamal Pirzaday
}

Working Paper 1521

November 2015

This Working Paper is issued under the supervision of the ERF Directorate. Any opinions expressed here are those of the author(s) and not those of the Koç University-TÜSİAD Economic Research Forum. It is circulated for discussion and comment purposes and has not been subject to review by referees.

\footnotetext{
KOÇ UNIVERSITY-TÜSİAD ECONOMIC RESEARCH FORUM

Rumelifeneri Yolu 34450 Sariyer/Istanbul
} 


\title{
Risk, Intermediate Input Prices and Missing Deflation During the Great Recession*
}

\author{
Engin Kara Ahmed Jamal Pirzada ${ }^{\dagger}$
}

October 1, 2015

\begin{abstract}
During the Great Recession, despite the large fall in output, inflation did not fall much. This is known as the missing deflation puzzle. In this paper, we develop and estimate a New Keynesian Dynamic Stochastic General Equilibrium model to provide an explanation for the puzzle. The new model allows for time-varying volatility in cross-sectional idiosyncratic uncertainty and accounts for the changes in intermediate goods prices. Our model can forecast the large fall in output and stable inflation during the Great Recession. We show that inflation did not fall much because intermediate goods prices were increasing during the Great Recession.
\end{abstract}

Keywords: Price Mark-up Shocks; Great Recession; Inflation; DSGE; Intermediate Inputs.

JEL Classification Numbers: E52, E58.

${ }^{*}$ We thank Raf Wouters and Tony Yates for helpful comments and suggestions.

${ }^{\dagger}$ Corresponding author: Department of Economics, Ozyegin University, Nisantepe Mah. Orman Sok. 34794 Cekmekoy, Istanbul, Turkey. e-mail: engin.kara@ozyegin.edu.tr. 


\section{Introduction}

New Keynesian Dynamic Stochastic General Equilibrium (DSGE) models have become an important tool for monetary policy analysis and forecasting at central banks and other policy institutions around the world. However, the failure of these models to forecast the behaviour of inflation and other key macroeconomic variables during the Great Recession has been interpreted as an evidence that the models run out of their usefulness. The two important papers in this regard are Ball and Mazumder (2011) and Hall (2011). Ball and Mazumder make their point by forecasting inflation during Great Recession using the New Keynesian Phillips Curve (NKPC), which determines inflation in the models. They find that the NKPC estimated from 1960 to 2007 cannot forecast inflation during the Great Recession. Hall criticises the NKPC on the basis that it fails to provide an explanation for the "missing deflation" puzzle. Missing deflation is characterised as the higher levels of actual inflation during the Great Recession than what the NKPC predicts. The NKPC relates inflation and economic activity. Given the depth and duration of the recession caused by the 2008 financial crisis, the NKPC would predict severe deflation. However, this did not happen and inflation remained positive.

The studies that use the New Keynesian model proposed by Smets and Wouters (2007) (henceforth SW) appear to be more optimistic about the forecasting ability of New Keynesian models than the single equation studies summarised above. The SW model is considered to be the state of the art instance of New Keynesian Economics.

It contains a variant of the NKPC and incorporates various real and nominal rigidities. For example, King and Watson (2012) find that the SW model can forecast 
inflation during the Great Recession but at the cost of having large exogenous price markup shocks. The presence of large price markup shocks in the model is a problem since, as Chari et al. (2009) note, it is difficult to interpret these shocks. ${ }^{1}$

A recent paper by Del Negro et al. (2015) (henceforth NGS) shows that the problem pointed out by King and Watson can easily be fixed by incorporating financial frictions as in Bernanke et al. (1999) (henceforth BGG). Indeed, NGS show that the resulting model generates a recession similar to the Great Recession and successfully captures "the near stability of inflation" without resorting to large price markup shocks. However, the improvement in the model's forecasting ability comes at the cost of greater degree of price stickiness. The estimated degree of price stickiness in the model is significantly larger than that suggested by the micro-evidence on prices (see Klenow and Malin (2011)). Increased price rigidity gives rise to a flatter Phillips curve, meaning that changes in marginal costs have little effect on inflation. As a consequence of the flat Phillips curve, even though their model predicts a substantial fall in marginal cost during the Great Recession, inflation does not fall much. Thus, their findings provide an explanation to the puzzle.

This paper offers an alternate explaination for the missing deflation puzzle. We argue that the reason for the stable inflation is the increasing intermediate goods prices during the Great Recession. To show this, as in NGS, we use the New Keynesian model with the BGG type financial frictions. But different from them, we incorporate intermediate materials prices to the SW model. Further, we remove

\footnotetext{
${ }^{1}$ Bils et al. (2012), by using micro-data on prices, show that the presence of large price mark-up shocks in the model leads to firm-level pricing that is inconsistent with the micro data, providing further evidence of the empirical invalidity of these shocks.
} 
the price mark-up shocks in the model and, following, Aoki (2001), De Walque et al. (2006) and Huang and Liu (2005), consider supply-side shocks that arise from changes in the relative intermediate goods prices. Another difference between our model and the model in NGS is that we model the idiosyncratic uncertainty faced by entrepreneurs differently. Let us briefly explain these differences.

To incorporate intermediate prices to the SW model, we divide the production into two sectors. In one of the sectors intermediate materials are produced and in the other the finished goods. We assume that intermediate materials are used as a factor input for the production of finished goods, while a small proportion of the intermediate materials is also needed to convert finished goods into consumption goods. Prices in both the sectors are set according to Calvo (1983) pricing. Inflation in the finished goods sectors depends on future marginal costs. We further assume that prices in the intermediate materials sector are subject to a sector specific shock. This shock is meant to capture the exogenous factors affecting the intermediate prices (e.g. Arab Spring). As a result, inflation in the intermediate goods sector depend on future marginal cost as well as the sector specific shock.

Turning to the second difference, as is well-known (see, e.g., Christiano et al. (2014)) (henceforth CMR), the BGG mechanism models the idiosyncratic uncertainty faced by entrepreneurs. The common assumption is to assume that the volatility of cross-sectional idiosyncratic uncertainty fluctuates over time. This measure of volatility is referred to as risk. In-line with CMR, we assume that the risk shock process has both unanticipated (or stochastic) and anticipated (or news) components. This modelling assumption of the risk shock is different from that made by NGS, who 
assume that the risk shock has only a stochastic component. There are two reasons for our modelling choice. First, several recent papers (e.g. CMR and Schmitt-Grohe and Uribe (2012)) show that accounting for the unanticipated component improves the empirical performance of the model significantly. Second, NGS consider only the stochastic component of the risk shock which is not sufficient to match the output dynamics during the Great Recession. To match the output dynamics, they assume a more complicated process for productivity shocks than that in the SW model. However, while their assumption gives rise to output dynamics that are very similar to those observed in the data, this comes at the cost of a very large government spending shock. The standard deviation of the government spending shock estimated in the NGS model is six times larger than that in the SW model. We prefer our approach as it matches the output dynamics as well as in the approach preferred by NGS but with a much smaller estimate for the government spending shock. The rest of the model is exactly the same as that in SW.

Next, we estimate the new model for the US data using Bayesian techniques. Finally, we compare the out of sample forecasts of inflation, output, marginal cost and the interest rate from our model to those of a variant of NGS model and of the Survey of Professional Forecasters (SPF). Our results suggest that our model forecasts the key macroeconomic variables as well as the NGS variant and better than the SPF. Importantly, it achieves this in a way that is consistent with the micro evidence on prices.

The BGG mechanism plays a crucial role in our model in that it helps to capture the drop in output at the beginning of the crisis. We find that both components 
of the risk shock process are important to capture the fall in output. With the unanticipated component of the risk shock only, the fall in output is muted and is very similar to that in the version of the model without the BGG mechanism. When we consider both components of the shock process the fall in output is in-line with the fall in output observed in the data. The intuitive explaination for this result is straightforward. Anticipating that the future uncertainty will increase, banks increase the interest rate on loans more. Increased interest rate depresses investment further, leading to a larger fall in output.

Turning to the inflation forecast, in the model with intermediate materials (henceforth SW-BGG-I) the degree of price stickiness is consistent with the micro data on prices and is less than in the NGS variant. The reason for this improvement is simple. Since SW-BGG-I accounts for the changes in intermediate prices, it forecasts marginal cost better. In SW-BGG-I, since intermediate materials are an input in production, marginal cost depends also on intermediate goods prices. During the Great Recession, intermediate prices were increasing. As a result, during the Great Recession, the marginal cost in our model remains considerably high, relative to that suggested by the NGS variant. To put it differently, SW-BGG-I suggests that the increase in intermediate prices during the Great Recession offset most of the decrease in marginal cost due to decreased economic activity. Consequently, prices in SWBGG-I do not need to be as sticky as those in NGS in order to explain the relatively muted response of inflation during the Great Recession.

This paper is closely related to an earlier paper by Coibion and Gorodnichenko (2013). These authors show that 'missing deflation' is a one-off event in response to 
rising oil prices. However, in our model, accounting for oil prices alone does not have a significant impact on inflation, as, at round 1\%, the share of oil in production is very small. Nevertheless, we reach similar conclusions using intermediate materials prices. As we will discuss in the text, the volatility in the prices of the intermediate materials closely tracks the volatility in the energy prices. The correlation between the two data series is as high as 0.84, suggesting that the factors driving changes in the energy prices may be the same as those underlying changes in the intermediate goods prices. Our paper differs further from that of Coibion and Gorodnichenko in its modelling approach. While their analysis is based on the expectations-augumented Phillips curve proposed by Friedman (1968), ours is carried out in a New Keynesian general equilibrium framework in which the Phillips curve is micro-founded. However, our findings further strengthen their conclusion by showing that their conclusion have a wider applicability and holds also in a new Keynesian general equilibrium model.

Another possible explaination for the stability of inflation during the Great Recession is noted by Christiano et al. (2015). At the start of the crisis, borrowing costs increased substantially. Therefore, financially constrained firms, which were previously financing their operating costs (e.g. wage bills) through borrowing, experienced an increase in their financing costs during the crisis. This increased firms' marginal costs and, therefore, kept the inflation stable.

In-line with the NGS and our results, Linde et al. (2015) also find BGG mechanism to play a crucial role in matching the output dynamics during the Great Recession. However, they question its usefulness in making accurate out-of-sample forecasts during normal times. 
The rest of the paper is organised as follows. Section 2 describes the model. Section 3 explains the estimation strategy. Section 4 presents the estimation results. Section 5 analyses the forecasting performance across the models with and without an intermediate sector. Finally, section 6 concludes.

\section{The Model}

The framework in this paper builds on the model in SW to allow for the inputoutput linkages between intermediate materials and finished goods and to account for the idiosyncratic uncertainty faced by entrepreneurs. While the production of intermediate materials requires labour and capital as inputs, the production of finished goods requires labour, capital and intermediate materials as inputs. Finished goods and a fraction of intermediate materials are combined to produce the final consumption goods that are consumed by the households. ${ }^{2}$ The two sectors also face the financial accelerator mechanism of BGG where financial market frictions arising through information asymmetry and agency costs affect the real side of the economy. In this we follow the work of NGS and CMR. Finally, the modelling of households and the monetary policy are standard New Keynesian.

In the rest of the section, we describe the behaviour of the firms followed with the description for the behaviour of the households and the monetary policy. The model is detrended using a deterministic trend and nominal variables are replaced

\footnotetext{
${ }^{2}$ The framework in this paper builds on Kara and Pirzada (2015). Kara and Pirzada exclude the BGG mechanism from the model we employ in this paper to make a general point that price markup shocks can indeed be replaced with fluctuations arising from changes in relative intermediate prices.
} 
with their real counterparts. Finally, the model is linearised around the stationary steady state of the detrended variables.

\subsection{Intermediate and Finished Goods}

There is a continuum of firms $f \in[0,1]$. We divide the unit interval into two sub-intervals representing each sector: finished goods sector $(s)$ and an intermediate sector $(m)$. Firms in both the sectors produce under an imperfectly competitive market and have monopoly power over a differentiated good. The share of the intermediate sector in the economy is given by $\left(1-\mu^{u}\right)$, while the share of the finished goods sector is $\mu^{u}$. The total intermediate production is denoted by $Y^{m}$. A fraction $\left(\mu^{c}\right)$ of the intermediate goods is used as input in the production of the finished goods. So, the share of the intermediate goods in the production of the finished goods is $\left(1-\mu^{u}\right) \mu^{c}$. The rest $\left(\bar{\alpha}=\left(1-\mu^{u}\right)\left(1-\mu^{c}\right)\right)$ is combined with the finished goods to produce the final consumption $\operatorname{good}^{3}\left(C_{t}\right)$, which enters to the utility function of the representative household. Each firm within the two sectors produces a single differentiated good, $Y^{s}(f)$ and $Y^{m}(f)$, which are combined to produce a final good in each sector, $Y^{s}$ and $Y^{m}$, respectively. The aggregation is done according to a Dixit-Stiglitz aggregator. The total consumption is given by:

$$
C_{t}=\left((1-\bar{\alpha})\left(Y_{t}^{s}\right)^{\frac{1}{1+\rho}}+\bar{\alpha}\left(Y_{t}^{m}\right)^{\frac{1}{1+\rho}}\right)^{1+\rho}
$$

\footnotetext{
${ }^{3}$ Such use of the intermediate materials can be thought as packaging and transportation of the finished goods before they could be sold as final consumption goods.
} 
where $\frac{1+\rho}{\rho}$ is the elasticity of substitution between the finished goods and the intermediate goods such that $Y_{t}^{s}$ and $Y_{t}^{m}$ are given by

$$
\begin{aligned}
Y_{t}^{s} & =\left[\int_{0}^{\mu}\left(Y_{f t}^{s}\right)^{1 /\left(1+\rho^{s}\right)} d f\right]^{1+\rho^{s}} \\
Y_{t}^{m} & =\left[\int_{\mu}^{1}\left(Y_{f t}^{m}\right)^{1 /\left(1+\rho^{m}\right)} d f\right]^{1+\rho^{m}}
\end{aligned}
$$

$\left(1+\rho^{f}\right) / \rho^{f}$ is the elasticity of substitution between the differentiated finished goods and $\left(1+\rho^{m}\right) / \rho^{m}$ is the elasticity of substitution between the differentiated intermediate goods. The corresponding price index is:

$$
P_{t}=\left((1-\bar{\alpha})^{\frac{1+\rho}{\rho}}\left(P_{t}^{s}\right)^{\frac{-1}{\rho}}+(\bar{\alpha})^{\frac{1+\rho}{\rho}}\left(P_{t}^{m}\right)^{\frac{-1}{\rho}}\right)^{-\rho}
$$

where $P_{t}$ is the general price index, $P_{t}^{m}$ is the price of intermediate materials and $P_{t}^{s}$ is the price level in the finished goods sector. In what follows, we will first describe the finished goods sector and then the intermediate sector. The demand for the finished goods sector and the intermediate goods sector is given by

$$
\begin{gathered}
Y_{t}^{s}=\left(\mu \frac{P_{t}}{P_{t}^{s}}\right)^{\frac{1+\rho}{\rho}} Y_{t} \\
Y_{t}^{m}=\left((1-\mu) \frac{P_{t}}{P_{t}^{m}}\right)^{\frac{1+\rho}{\rho}} Y_{t}
\end{gathered}
$$

In the finished goods sector, with a constant returns to scale (CRS) technology, firms have a production function of the form:

$$
\left.Y_{t}^{s}(f)=Y_{t}^{m}(f)^{\mu^{c}\left(1-\mu^{u}\right)}\left(A_{t} K_{t}^{s}(f)^{\alpha}\left[\gamma^{t} L_{t}^{s}(f)\right]^{1-\alpha}\right)^{\left(1-\mu^{c}\left(1-\mu^{u}\right)\right.}\right)-\gamma^{t} \Phi+E_{t}
$$

where $Y_{t}^{m}(f)$ denotes intermediate sector goods used as input by firm $f$ in the finished goods sector, $L_{t}^{s}(f)$ is a composite of labour input, $K_{t}^{s}(f)$ is capital services and $\Phi$ is the fixed cost. $\gamma^{t}$ represents the labour-augmenting deterministic growth 
rate in the economy and $\alpha$ is the share of capital in the production function. $A_{t}$ is the productivity shock which follows an $\mathrm{AR}(1)$ process with parameters $\rho_{a}$ and $\sigma_{a} . E_{t}$ is a stochastic shock process that is meant to capture changes in production that arise from external factors, such as unusually cold winters and rare disasters. It, different from a productivity shock, does not affect marginal cost directly. A variance decomposition analysis for our estimated model suggests that this shock explains about $2 \%$ of the fluctuations in total output. We assume that the shock affects the finished goods sector only. But it has an indirect effect on the intermediate goods sector. An unusually cold winter would cause a disruption in the production of the finished goods, reducing the demand for intermediate goods as well. In an alternative setting, we assume that the shock affects both the finished goods sector and the intermediate goods sector directly. Doing so does not change our main results significantly. The log-linearised version of the production function in equation (7) is:

$$
y_{t}^{s}=\phi_{p}\left(\mu^{u}\left(1-\mu^{c}\right) y_{t}^{m}+\left(1-\mu^{u}\left(1-\mu^{c}\right)\right)\left(\alpha k_{t}^{s}+(1-\alpha) L_{t}^{s}+a_{t}\right)\right)+e_{t}
$$

where $e_{t}=\ln E_{t}$ and $a_{t}=\ln A_{t}$. Unlike the finished goods sector, firms in the intermediate sector have labor and capital as the only two factor inputs such that their production function is given by:

$$
Y_{t}^{m}=A_{t}\left(K_{t}^{m}\right)^{\alpha}\left(\gamma^{t} L_{t}^{m}\right)^{1-\alpha}-\gamma^{t} \Phi
$$

where $L_{t}^{m}(f)$ is a composite of labour input and $K_{t}^{m}(f)$ is capital services used in the intermediate sector. Log-linearising Equation (9) gives:

$$
y_{t}^{m}=\phi_{p}\left(\alpha k_{t}^{m}+(1-\alpha) L_{t}^{m}+a_{t}\right)
$$

Prices in both the sectors are set according to Calvo pricing with no ad-hoc 
partial indexation. Log-linearisation of the aggregate price index in equation (4) is represented as:

$$
0=\bar{\alpha} \bar{p}_{t}^{m}+(1-\bar{\alpha}) \bar{p}_{t}^{s}
$$

where $\bar{p}_{t}^{s}=p_{t}^{s}-p_{t}$ is the relative price level in the finished goods sector and $\bar{p}_{t}^{m}=$ $p_{t}^{m}-p_{t}$ is the relative price level in the intermediate goods sector. Profit maximisation by the price-setting firms in the finished goods sector gives the following sectoral NKPC:

$$
\pi_{t}^{s}=\beta \gamma^{1-\sigma_{c}} \pi_{t+1}^{s}+\kappa\left(\bar{m} c_{t}^{s}-\bar{p}_{t}^{s}\right)
$$

where $\kappa$ is the slope coefficient of the form:

$$
\kappa=\frac{\left(1-\zeta_{p} \beta \gamma^{1-\sigma_{c}}\right)\left(1-\zeta_{p}\right)}{\zeta_{p}}
$$

and $\bar{m} c_{t}^{s}$ is the real marginal cost in the finished goods sector:

$$
\bar{m} c_{t}^{s}=\left(1-\mu^{c}\left(1-\mu^{u}\right)\right)\left(\alpha r_{t}^{k}+(1-\alpha) w_{t}-a_{t}\right)+\left(\mu^{c}\left(1-\mu^{u}\right)\right) \bar{p}_{t}^{m}
$$

where $\zeta_{p}$ in equation (16) is the Calvo parameter for price stickiness. $\beta$ is the discount factor. $\sigma_{c}$ represents the elasticity of intertemporal substitution such that when it is above unity consumption and labor hours are complements to each other. In equation (17) $w_{t}$ is the real wage and $r_{t}^{k}$ is the real rental rate of capital.

The NKPC in the intermediate sector is given by:

$$
\pi_{t}^{m}=\beta \gamma^{1-\sigma_{c}} \pi_{t+1}^{m}+\kappa^{m}\left(\bar{m} c_{t}^{m}-\bar{p}_{t}^{m}\right)+\epsilon_{t}^{a^{f}}
$$

where $\kappa^{m}$ is the slope coefficient of the form:

$$
\kappa^{m}=\frac{\left(1-\zeta_{p}^{m} \beta \gamma^{1-\sigma_{c}}\right)\left(1-\zeta_{p}^{m}\right)}{\zeta_{p}^{m}}
$$

where $\zeta_{p}^{m}$ is the Calvo parameter for price stickiness specific to the intermediate 
sector. $\bar{m} c_{t}^{m}$ is the real marginal cost in the intermediate sector:

$$
\bar{m} c_{t}^{m}=\alpha r_{t}^{k}+(1-\alpha) w_{t}-a_{t}
$$

where $\epsilon_{t}^{a^{f}}$ is an exogenous shock to the intermediate materials prices and follows an $\mathrm{AR}(2)$ process of the form in equation (18):

$$
a_{t}^{f}=\rho_{a^{f}} a_{t-1}^{f}+\rho_{a^{f}}^{2} a_{t-2}^{f}+\epsilon_{t}^{a^{f}}
$$

The aggregate output, labour and capital in logs are given by

$$
\begin{aligned}
& y_{t}=\mu^{u} y_{t}^{s}+\left(1-\mu^{u}\right) y_{t}^{m} \\
& L_{t}=\mu^{u} L_{t}^{s}+\left(1-\mu^{u}\right) L_{t}^{m} \\
& k_{t}=\mu^{u} k_{t}^{s}+\left(1-\mu^{u}\right) k_{t}^{m}
\end{aligned}
$$

whereas the linearised aggregate marginal cost is given by:

$$
m c_{t}=(1-\bar{\alpha}) \bar{m} c_{t}^{s}+\bar{\alpha} \bar{m} c_{t}^{m}
$$

In the next subsection, we will describe the financial accelerator mechanism which is identical to that in NGS.

\subsection{The Financial Accelerator Mechanism and the Risk Shock}

The introduction of financial frictions in the model alters the arbitrage equation. The arbitrage equation between the return on capital and the riskless rate in SW is replaced with an equation for capital returns and an equation for the spread between capital returns and riskless rate. Equation determining the spread is:

$$
E_{t}\left[\tilde{R}_{t+1}^{k}-R_{t}\right]=b_{t}+\zeta_{s p, b}\left(q_{t}^{k}+\bar{k}_{t}-n_{t}\right)+\tilde{\sigma}_{w, t}
$$


Equation (21) has the SW arbitrage equation as a special case when the parameter, $\zeta_{s p, b}$, associated with the ratio of the value of installed capital to net worth, $\frac{Q_{t+i-1}^{k} \bar{K}_{t+i-1}}{N_{t+i-1}}$, is zero. $q_{t}^{k}$ is the real value of the capital stock. $\tilde{\sigma}_{w, t}$ is the risk shock and $\tilde{R}_{t}^{k}$ denotes capital return to the entrepreneurs. $\tilde{R}_{t}^{k}$ can also be interpreted as required returns on capital, since Entrepreneurs' borrowing cost within the model always equals $\tilde{R}_{t}^{k}$, given by:

$$
\tilde{R}_{t}^{k}-\pi_{t}=\frac{r_{*}^{k}}{r_{*}^{k}+(1-\delta)} r_{t}^{k}+\frac{1-\delta}{r_{*}^{k}+(1-\delta)} q_{t}^{k}-q_{t-1}^{k}
$$

$n_{t}$ in (21) is the net worth of entrepreneurs expressed as:

$$
n_{t}=\zeta_{n, \tilde{R}^{k}}\left(\tilde{R}_{t}^{k}-\pi_{t}\right)-\zeta_{n, R}\left(R_{t-1}-\pi_{t}\right)+\zeta_{n, q^{k}}\left(q_{t-1}^{k}+\bar{k}_{t-1}\right)+\zeta_{n, n} n_{t-1}
$$

Following CMR and Fernandez-Villaverde et al. (2011), we assume the following process for the risk shock:

$$
\tilde{\sigma}_{w, t}=\rho_{\tilde{\sigma}} \tilde{\sigma}_{w, t-1}+u_{\tilde{\sigma}, t}
$$

where

$$
u_{\tilde{\sigma}, t}=\rho_{\tilde{\sigma}, n} u_{\tilde{\sigma}, t-1}+\epsilon_{\tilde{\sigma}, t}
$$

After a straightforward algebra, the last two equations can be rewritten as:

$$
\tilde{\sigma}_{w, t}=\rho_{\tilde{\sigma}} \tilde{\sigma}_{w, t-1}+\epsilon_{\tilde{\sigma}, t}+\rho_{\tilde{\sigma}, n} \epsilon_{\tilde{\sigma}, t-1}+\rho_{\tilde{\sigma}, n}^{2} \epsilon_{\tilde{\sigma}, t-2}+\ldots+\rho_{\tilde{\sigma}, n}^{n} \epsilon_{\tilde{\sigma}, t-n} \ldots
$$

where $0<\rho_{\tilde{\sigma}}<1$ and $\epsilon_{\tilde{\sigma}, t}$ is iid (independent and identically distributed) and denotes the unanticipated component of $\tilde{\sigma}_{w, t}$. Following CMR, we assume that $n$ can take values up to 8 . We call $\epsilon_{\tilde{\sigma}, t-n}$, where $n=1 \ldots 8$, as an anticipated component whose value was revealed in $t-n$. Thus, at time $t$ the realisation of the shock $\tilde{\sigma}_{w, t}$ is influenced by the combined impact of both the unanticipated and the anticipated components. To understand this shock process, consider a financial shock $\left(\epsilon_{\tilde{\sigma}, t}\right)$ hitting the economy 
in period $t$. This shock will indirectly affect the economy through its effects on $\tilde{\sigma}_{w, t+j}$ for the next $j$ periods. The shock will receive less weight the further agents look into the future. Given that agents are forward-looking, they will take into account the effects of these shocks on future variables in their current choices. Furthermore, as Christiano et al. (2010) argue, such generalised shock process also helps to "tackle the deep-seated misspecification problems in DSGE models." The rest of the model equations are the same as in the SW model and are listed in the Appendix.

\section{Estimation Strategy}

We estimate the model in this paper (SW-BGG-I) and a version of the NGS model (henceforth SW-BGG) using Bayesian estimation techniques. In this we follow Smets and Wouters (2003). ${ }^{4}$ The SW-BGG differs from the model in NGS only in its detrending approach and the shock process for the risk shock. While the SWBGG assumes a deterministic trend in productivity, as in the SW model, the NGS model considers both deterministic and stochastic trends in productivity. Moreover, unlike NGS, the SW-BGG also allows for anticipated component in the risk shock process. As noted before, results from the NGS specification come at the cost of large government spending shocks.

The data from 1981Q1 to 2008Q3 is used to estimate the models, while forecasting is done over 2008Q4-2009Q4. We use ten macroeconomic series at the quarterly frequency for the US economy. Seven of the data series are identical to the SW:

\footnotetext{
${ }^{4}$ We ensure an acceptance rate of around $30 \%$ and allow for 250,000 replications for the Metropolis-Hastings algorithm. Estimation is done in Dynare 4.3.3.
} 
the log difference of real GDP, real consumption, real investment, real wage, log hours worked, log difference of the GDP deflator and the federal funds rate. Data for quarterly credit spread and 10-year inflation expectations is also included as in the NGS. Credit spread is measured by the difference between the interest rate on BAA-rated corporate bonds and the 10 year US government bond rate. Blue Chip Economic Indicators survey and the Survey of Professional Forecasters are used to obtain data for 10-year inflation expectations. Adding 10-year inflation expectations data is helpful since, as pointed out in Del Negro and Eusepi (2011) and Kiley (2008), inflation expectations contain information about publics' belief regarding Fed's inflation objectives. We further include data on the log difference of real intermediate materials prices. Seasonally adjusted intermediate price data is obtained from the St. Louis FED database ${ }^{5}$ which is then deflated using the GDP deflator. The measurement equations relating the data to the model variables are:

\footnotetext{
${ }^{5}$ Producer Price Index by Commodity Intermediate Materials: Supplies \& Components (PPIITM).
} 


$$
\begin{array}{ll}
\text { OutputGrowth } & =\gamma+100\left(y_{t}-y_{t-1}\right) \\
\text { ConsumptionGrowth } & =\gamma+100\left(c_{t}-c_{t-1}\right) \\
\text { InvestmentGrowth } & =\gamma+100\left(i_{t}-i_{t-1}\right) \\
\text { RealWageGrowth } & =\gamma+100\left(w_{t}-w_{t-1}\right) \\
\text { HoursWorked } & =\bar{l}+100 l_{t} \\
\text { Inflation } & =\pi_{*}+100 \pi_{t} \\
\text { FederalFundsRate } & =R_{*}+100 R_{t} \\
\text { Spread } & =S P_{*}+E_{t}\left[\tilde{R}_{t+1}^{k}-R_{t}\right] \\
\text { 10yrInflExp } & =\pi_{*}+E_{t}\left[\frac{1}{40} \Sigma_{k=1}^{40} \pi_{t+k}\right] \\
\text { IntermediateInflation } & =\gamma+100\left(\bar{p}_{t}^{m}-\bar{p}_{t-1}^{m}\right)
\end{array}
$$

where steady state of the quarterly hours worked, inflation and nominal interest rates are denoted by $\bar{l}, \pi_{*}=100\left(\Pi_{*}-1\right)$ and $R_{*}=100\left(\beta^{-1} \gamma^{\sigma_{c}} \Pi_{*}-1\right)$, respectively. All the variables are expressed in percent.

Table 4 and Table 5 summarise our assumptions regarding prior distributions. Priors for most of the model parameters are similar to SW. Calvo parameters for intermediate and finished goods sectors follow Beta distribution with standard deviation of 0.10 . However, prices in the intermediate sector are more flexible with a prior mean of 0.40 relative to the finished goods sector with a prior mean of 0.75 . Contrary to the SW-BGG, price mechanism in SW-BGG-I model does not include price indexation. 
In the SW-BGG, all the shock processes follow $\mathrm{AR}(1)$ process except for the risk shock, government spending shock and the two mark-up shocks. Both the price and wage mark-up shocks follow an ARMA(1,1) process, as in the SW model. The risk shock follows a process that allows for anticipated signals as explained in equation (24).

The shock processes in the SW-BGG-I are identical to SW-BGG except that the price mark-up shock in the SW-BGG is replaced with the two supply side shocks. We interpret $\epsilon^{a^{f}}$ in equation (15) as shocks arising from changes in the real intermediate prices. Arguably, changes in the intermediate prices are driven by the factors underlying changes in the energy prices. Figure 1 plots the log of real energy and as well as the real intermediate materials price data. It can be seen that the volatility in the prices of the intermediate materials closely tracks the volatility in the energy prices. The correlation between the first difference of the two data series is as high as 0.78. The persistence parameters of the two shocks follow a beta prior distribution with mean 0.50 and standard deviation 0.20 . The standard deviation of the intermediate input shock, $\sigma_{a^{f}}$, is specified an Inverse Gamma distribution with mean 2.50 and standard deviation 2.0. $\sigma_{e i}$ also follows an Inverse Gamma distribution with mean 0.10 and standard deviation 2.0.

Following the evidence provided by Strassner and Moyer (2002), the parameters of the intermediate sector, $\mu^{u}$ and $\mu^{c}$, are calibrated such that the share of intermediate materials as input in finished goods production is $20 \%$. The share of intermediate materials in producing final consumption good is kept fixed at $2 \%$. Note that in the SW-BGG, as it is the case in SW, we assume that the curvature of the Kimball 
aggregator in the goods market $\left(\epsilon_{p}\right)$ is 10. In the SW-BGG-I we assume that the aggregation is done according a Dixit and Stiglitz aggregator and therefore $\epsilon_{p}$ equals 1. Following Woodford (2003) and De Walque et al. (2006), elasticity of substitution between the finished and the intermediate goods, $(1+\rho) / \rho$, is also assumed to equal 1. Table 2 reports the values for the parameters that are fixed in estimation.

Table 1: Exogenous parameter values

\begin{tabular}{clc}
\hline \hline Parameter & Definition & Values \\
\hline$\beta$ & Discount Rate & 0.9995 \\
$\gamma$ & Trend Growth Rate & 1.004 \\
$\delta$ & Depreciation rate & 0.025 \\
$\epsilon_{w}$ & Curvature of the Kimball labor market aggregator & 10 \\
$g_{y}$ & Government spending-output ratio & 0.18 \\
$\mu^{c}\left(1-\mu^{u}\right)$ & Share of intermediate materials in firms' production & 0.20 \\
$\left(1-\mu^{c}\right)\left(1-\mu^{u}\right)$ & Share of intermediate materials in consumption goods & 0.02 \\
\hline \hline
\end{tabular}

Turning to the parameter values for the financial sector, following CMR, we calibrate survival rate of entrepreneurs $(\tau)$ as $97.28 \%$ and percentage of businesses going bankrupt $\left(F^{*}(\bar{\omega})\right)$ as $1 \%$ annually. Rental rate of capital is assumed to be 0.045 to match the risk premium, equity to debt ratio and the return on capital in the steady state. $\operatorname{Var}(\log \omega)$ is set at 0.24 . Different from CMR, $\mu^{e}$ is endogenous in our model and has a steady state value of 0.31 , which is less than the value of 0.94 assumed in CMR. Parameters on the net worth equation are also endogenous and are derived in the model. All these numbers are summarised in Table 1. 
Table 2: Exogenous parameter values

Entrepreneurs:

$\begin{array}{cll}F^{*}(\bar{\omega}) & \text { Percent of Businesses that go into Bankruptcy in a year } & 0.01 \\ \operatorname{Var}(\log \omega) & \text { Variance of the log-normally distributed i.i.d shock } & 0.24 \\ \tau & \text { Fraction of Entrepreneurs surviving to the next period } & 0.9728 \\ \mu^{e} & \text { Monitoring costs } & 0.31 \\ r^{k} & \text { Rental rate of capital } & 0.045\end{array}$

We estimate the two financial sector parameters in equations $(21)$ and $(27), \zeta_{s p, b}$ and $S P_{*}$, respectively. Priors for the financial sector parameters are set in-line with NGS and are given in Table 5. $S P_{*}$ follows a Gamma distribution with prior mean of 2 and standard deviation of $0.10 . \zeta_{s p, b}$ is assumed to follow a Beta distribution with mean of 0.05 and standard deviation of 0.005 . The three parameters related to the risk shock are the persistence of the shock process $\left(\rho_{\bar{\sigma}}\right)$, the standard deviation of the shock $\left(\sigma_{\bar{\sigma}}\right)$ and the parameter on the anticipated components of the risk shock $\left(\rho_{\bar{\sigma}, n}\right)$. $\rho_{\bar{\sigma}}$ is specified a Beta distribution with mean 0.75 and standard deviation $0.15 . \sigma_{\bar{\sigma}}$ has mean 0.05 and standard deviation of 4 with an Inverse Gamma distribution. $\rho_{\bar{\sigma}, n}$ is also specified an Inverse Gamma distribution with mean 1 and standard deviation 2.

Prior distributions of the remaining parameters in the model are identical to the SW. 


\section{Estimation Results}

The estimated values for the structural parameters are reported in Table 4. Table 4 also includes the prior and posterior standard deviation for the corresponding parameters.

In the SW-BGG-I, the price stickiness parameter, $\xi_{p}$, in the finished goods sector is 0.59 suggesting an average age of the price contract of 2.4 quarters, which is consistent with the evidence reported in (Klenow and Malin, 2011). Again consistent with the findings reported in Klenow and Malin, with the estimated value of $\xi_{p}^{m}$ of 0.46, prices in the intermediate sector are more flexible than those in the finished goods sector. In the SW-BGG, in-line with the estimates of NGS, $\xi_{p}$ is estimated to be 0.83 , a value that is larger than that suggested by the micro-evidence on prices. These numbers imply that the average age of price contracts in the SW-BGG-I is almost one third of that in the SW-BGG (6 quarters). As discussed in NGS and we will discuss later in text, NGS's conclusions rely on large duration of price contracts.

A few other estimates are worth commenting on. The estimated degree of habit persistence $(h)$ is larger in SW-BGG-I (0.71) than in the SW-BGG (0.34). Contrary to SW-BGG, the elasticity of intertemporal substitution $\left(\sigma_{c}\right)$ is estimated at close to 1 for the SW-BGG-I, while it is 1.9 in the SW-BGG. The estimated degree of wage indexation $\left(\iota_{w}\right)$ in the SW-BGG-I $(0.22)$ is lower than that in the SW-BGG (0.39). Both the models suggest strong reaction to inflation by the FED. The estimate of the parameter on inflation $\left(r_{\pi}\right)$ in the Taylor rule is around 1.35 across the two models. In both models, the parameter on the change in output gap $\left(r_{\Delta y}\right)$ receives a larger weight than the parameter on the output gap $\left(r_{y}\right)$. Degree of interest rate smoothing 
$\left(\rho_{r}\right)$ is also very high for both the models and is estimated to be more than 0.70 . The estimates for the two financial sector parameters, $S P_{*}$ and $\zeta_{s p, b}$, as well as the parameters of the risk shock, $\rho_{\bar{\sigma}}, \sigma_{\bar{\sigma}}$ and $\rho_{\bar{\sigma}, n}$, are almost identical across the two models.

The supply side shocks in the intermediate sector are relatively less persistent than the price markup shock in the SW-BGG. Persistence of intermediate input shock, $\rho_{a^{f}}$, is estimated at 0.62 while it is only 0.17 and 0.01 for the persistence parameters, $\rho_{e i}$ and $\rho_{e i^{1}}$, respectively, of the $\sigma_{e i}$ shock. The persistence of the price markup shock, $\rho_{\pi}$, in the SW-BGG, on the other hand, is much larger at 0.81 . The estimated standard deviation of the price mark-up shock in the SW-BGG is in-line with that of the SW. Reflecting the highly volatile nature of the energy prices, the standard deviation of the intermediate input shock in the SW-BGG-I is large at around 1.5 .

\section{Forecasts Comparison During the Great Reces- sion}

This section compares the out-of-sample forecasting performance of the two models over the Great Recession period. As noted above, we estimate the model for the period from 1981Q1 to 2008Q3 and then use the estimated model to forecast for the period from 2008Q4 to 2009Q4. The data on spread and interest rate was already available for the first forecast period but not for the remaining variables. Therefore,

in-line with the NGS, the forecast is made with the information set, $Y_{1: T+}$, available 
as of December 31, 2008, including the two additional data points for spread and interest rate in the first period of forecast.

Figure 3 plots the forecast results for inflation and output from the two models, the SW-BGG and the SW-BGG-I, along with the actual data for inflation and output. We also include the forecast from the Survey of Professional Forecasters (SPF) for comparison. Let us first consider the output forecasts. As the figure shows, the forecast for output is similar across the SW-BGG and the SW-BGG-I. Both these models forecast output very well. Just as in the actual output, both models predict a substantial fall in output at the beginning of the crisis. Output then recovers relatively quickly, although actual output recovers faster than predicted by the models. The slower recovery in the models relative to the data can be attributed to the unconventional monetary and fiscal policy measures taken during the period of the Great Recession. The US economy experienced three rounds of large scale asset purchases and as well as a large fiscal stimulus. Since the model in this paper is estimated for the pre-crisis period, this information on the unconventional nature of both the monetary and fiscal policy is not accounted for. The SPF does poorly and does not forecast significant change in output.

Likewise, both the models also forecast inflation equally well. However, the SWBGG forecast comes at the cost of high price rigidities. In both the models, inflation starts recovering immediately after the economy is out of the recession (2009 Quarter 3) and stays positive henceforth. Note, unlike the two variants of the New Keynesian DSGE model studied in this paper, the SPF does not predict any substantial change in inflation during the Great Recession. Inflation forecast from the SPF remains 
considerably high relative to the actual. Table 3 provides the Root Mean Square Error (RMSE) for the variable forecasts over the Great Recession.

Table 3: Root Mean Square Error (RMSE) over Forecast Period

\begin{tabular}{llll}
\hline \hline Variable & SW-BGG-I & SW-BGG & SPF \\
\hline Inflation & 0.03 & 0.03 & 0.12 \\
Output Growth & 0.93 & 0.93 & 0.47 \\
Marginal Cost & 0.42 & 1.25 & - \\
Interest Rate & 0.00 & 0.02 & 0.02 \\
\hline \hline
\end{tabular}

We also plot the forecasts for the interest rates from the two models and the SPF. These are reported in Figure 6. The interest rate forecast from the SW-BGG-I closely follows the data. As the figure shows, in-line with the behaviour of the interest rates during the forecast period, the interest rate forecast is around zero throughout the Great Recession. The SPF, on the other hand, forecasts an immediate increase in the interest rates. However, in the SW-BGG-I, allowing for increased uncertainty by including anticipated component in the risk shock process is crucial for generating data consistent interest rate forecasts. When we replace our risk shock process with that in the NGS, both the models forecast interest rates to start increasing immediately into the forecast period.

Taken together, the above findings suggest that the SW-BGG-I forecasts the key macroeconomic variables relatively better than the SW-BGG and the SPF. Importantly, this is true even though the degree of price stickiness in the SW-BGG-I is lower than in the SW-BGG. Thus, the SW-BGG-I provides an explanation for the 
'missing deflation' puzzle in a way that is consistent with the microevidence on prices. In what follows we will explain the findings from the SW-BGG and SW-BGG-I in more detail. We will first focus on the output forecast and then the inflation forecast.

\subsection{Output Forecasts}

In the two models, SW-BGG and SW-BGG-I, both the anticipated and unanticipated components of the risk shock play an important role in capturing the full magnitude of the drop in output at the onset of the crisis. When we remove the anticipated components of the shock process, as shown in Figure 5, the decline in output is much smaller across both the models. Inflation in the two models also falls less in response to the muted output forecast. The intuition behind these results are as follows. Let us first focus on the unanticipated component of the shock process. When the shock hits the economy, the uncertainty in the economy increases. This results in banks increasing the interest rate charged on loans to the entrepreneurs. With increased interest rates, entrepreneurs borrow less, leading to a decrease in in-

vestment. Consequently, output falls following a contraction in investment. Adding an anticipated element to the shock process amplifies the fall in output, since the anticipation that the future uncertainty will increase leads banks to further increase the interest rate on loans. Increased interest rates depresses investment further, leading to a larger fall in output. 


\subsection{Inflation Forecasts}

To understand the reasons for the improved inflation forecast vis-a-vis price rigidities, we examine the behaviour of marginal costs in the two models. Doing so is helpful since in both models inflation is determined by future marginal costs. Figure 2 and Figure 7 plots the smoothed marginal costs (MC) for the two models over the full sample period, $Y_{1: T_{\text {full }}}$, and as well as the out of sample forecast, respectively.

Two points must be made about the comparison between the marginal costs in the SW-BGG-I and those in the SW-BGG. First, marginal costs in both models behave very differently. The SW-BGG predicts much lower marginal cost during the Great Recession than the SW-BGG-I. Second, the difference between the marginal costs forecast and the smoothed marginal cost is larger in the SW-BGG than in the SW-BGG-I, indicating larger forecast errors in the SW-BGG (Table 3). Smaller ex-post forecast errors in the case of SW-BGG-I provides support to the mechanism at work in the model.

The first observation brings up a natural question: why is the behaviour of the marginal cost in the models with and without the intermediate sector so different? The answer to this question is straightforward. As Figure 1 shows, real intermediate prices increased substantially before and during the Great Recession. Since intermediate prices directly affect the marginal cost in the SW-BGG-I (see equation 17), increasing intermediate prices almost completely offset the fall in the marginal cost following the sharp contraction in the economic activity. Therefore, given that inflation depends on marginal costs and that the fall in marginal cost in the SW-BGG-I is muted, the SW-BGG-I does not need large degree of price stickiness to match near 
stability of inflation data. However, since the marginal cost in the absence of intermediate prices falls sharply, large degree of price sickness is necessary for matching the observed inflation dynamics in the SW-BGG model.

Figure 4 plots the inflation forecast when price rigidities in both the models are exactly similar. In-line with the finding of NGS, the role played by the Calvo parameter in keeping the inflation forecast stable is much more profound in the SWBGG. If we calibrate the Calvo parameter in the SW-BGG with the value suggested by the SW-BGG-I, the SW-BGG predicts persistent deflation. On the other hand, calibrating the Calvo parameter with the value suggested by the SW-BGG (i.e. 0.83) dampens the effect of the prevalent slack in the economy on inflation. This causes the SW-BGG-I to forecast relatively higher inflation than for the Calvo parameter of 0.59 .

It is important to note that the price mark-up shocks are meant to capture the changes in energy prices (see, e.g. NGS). As we discussed in detail in Kara and Pirzada (2015), these shocks can have very different implications for the marginal costs than the intermediate input shocks. When price mark-ups increase, marginal cost must fall. This is because of the fact that prices are sticky. A positive mark-up shock must, therefore, be compensated by reduced marginal cost. Firms achieve this by lowering their output. Since decrease in the output leads to a fall in the prices of the factor inputs, firms' marginal cost declines.

On the contrary, intermediate input shocks lead to an increase in marginal cost, since intermediate materials are an additional cost component of the firms' marginal cost. Figure 8 highlights how these two shocks have different implications for the 
economy even when the inflation dynamics in response to the two shocks are almost identical. In SW-BGG-I, output contracts twice as much as in the SW-BGG which causes labour and capital to also fall more than in the SW-BGG. Thus the responses to the exogenous changes in the intermediate prices are amplified when an intermediate materials producing sector is incorporated in the SW-BGG framework.

\section{Conclusions}

In this paper, we have reformulated the standard New Keynesian model to include a Bernanke-Gertler-Gilchrist financial accelerator mechanism and to account for the changes in intermediate materials prices. In the new model, intermediate materials are used as an additional factor input in the production of finished goods. A fraction of intermediate goods are also combined with the finished goods to produce the final consumption good. We have estimated the model for the period from 1981Q1 to 2008Q3 using the quarterly US data. The estimated model is then used to forecast over the period from 2008Q4 to 2009Q4 to see if the reformulated model can account for the evolution of the key macroeconomic variables during the Great Recession. The forecasting ability of a version of the model without intermediate sector has already been tested by Del Negro et al. (2015). These authors show that adding financial frictions proposed by Bernanke et al. (1999) significantly improves the forecasting performance of the model but at the cost of greater price stickiness than that suggested by the micro-data on prices.

We have shown that accounting for the changes in intermediate prices improves 
the forecasting ability of the model further. Importantly, our model achieves this with an empirically relevant degree of price stickiness. The key difference across the two models is that in the model with intermediate sector marginal cost does not decline during the Great Recession unlike in the model without intermediate sector. This is because of the fact that during the Great Recession intermediate prices were increasing. Since intermediate materials in our model are required to produce finished goods, during the Great Recession, the marginal cost in our model does not fall as much as it does in the model without intermediate materials. As a consequence, despite the substantial drop in output, just as in the data, inflation does not fall much, providing an explanation for the "missing deflation" puzzle. 


\section{References}

An, S. and Schorfheide, F. 2007. "Bayesian Analysis of DSGE Models," Econometric Reviews, 26(2-4): 113-172.

Aoki, K. 2001. "Optimal Monetary Policy Responses to Relative-Price changes," Journal of Monetary Econoics, 48: 55-80.

Ball, L. M. and Mazumder, S. 2011. "Inflation Dynamics and the Great Recession," NBER Working Paper No. 17044.

Bernanke, B., Gertler, M. and Gilchrist, S. 1999. "The Financial Accelerator in a Quantitative Business Cycle Framework," Handbook of Macroeconomics, ed. by J. B. Taylor and M. Woodford, North Holland, Amsterdam, vol. 1C.

Bils, M., Klenow, P. J. and Malin, B. A. 2012. "Testing for Keynesian Labor Demand," NBER Chapters, in: NBER Macroeconomics Annual 2012, 27: 311-349.

Calvo, Guillermo. 1983. "Staggered prices in a utility-maximizing framework," Journal of Monetary Economics, 12 (3): 383-398.

Chari, V. V., Kehoe, P. J. and McGrattan, E. R. 2009. "New Keynesian Models: Not Yet Useful for Policy Analysis," American Economic Journal: Macroeconomics, $1: 1,242-266$.

Christiano, L., Motto, R. and Rostagno, M. 2010. "Financial Factors in Economic Fluctuations," ECB Working Paper No. 1192. 
Christiano, L., Motto, R. and Rostagno, M. 2014. "Risk Shocks," American Economic Review, 104(1): 27-65.

Christiano, L. J., Eichenbaum, M. S. and Trabandt, M. 2015. "Understanding the Great Recession" American Economic Journal: Macroeconomics, 7(1): 110-167.

Coibion, O. and Gorodnichenko, Y. 2013. "Is the Phillips Curve Alive and Well After All? Inflation Expectations and the Missing Disinflation," NBER Working Paper No. 19598.

De Walque, G., Smets, F. R. and Wouters, R. 2006. "Price Shocks in General Equilibrium: Alternative Specifications," CESifo Economic Studies, 52: 153-176.

Del Negro, M. and Eusepi, S. 2011. "Fitting Observed Inflation Expectations," Journal of Economic Dynamics and Control, 35(12): 2105-2131.

Del Negro, M., Giannoni, M. P. and Schorfheide, F. 2015. "Inflation in the Great Recession and New Keynesian Models," American Economic Journal: Macroeconomics, $7(1)$ : 168-196.

Fernandez-Villaverde, J., Guerron-Quintana, P., Rubio-Ramirez, J. F. and Uribe, M. 2011. "Risk Matters: The Real Effects of Volatility Shocks," American Economic Review, 101(6): 2530-2561.

Friedman, M. 1968. "The Role of Monetary Policy," American Economic Review, 58: $1-17$.

Hall, R. E. 2011. "The Long Slump." American Economic Review, 101: 431469. 
Huang, K. X. D. and Liu, Z. 2005. "Inflation Targeting: What Inflation Rate to Target?," Journal of Monetary Economics, 52(8): 1435-1462.

Kara, E. and Pirzada, A. J. 2015. "Fundamental Inflation and Intermediate Input Prices," Working Paper, University of Bristol.

Kiley, M. T. 2008. "Monetary Policy Actions and Long-Run Inflation Expectations," FEDS Working Paper No. 2008-03.

King, R. G. and Watson, M. W. 2012. "Inflation and Unit Labor Cost," Journal of Money, Credit and Banking, Blackwell Publishing, 44: 111-149.

Klenow, P. J. and Malin, B. A. 2011. "Microeconomic Evidence on Price-Setting," Handbook of Monetary Economics, 3A, B. Friedman and M. Woodford ed.: Elsevier, 231-284.

Linde, J., Smets, F. and Wouters, R. (forthcoming). "Macro Models Used at Central Banks and New Challenges," Handbook of Macroeconomics, J. B. Taylor and H. Uhlig.

Schmitt-Grohe, S. and Uribe, M. 2012. "What's News in Business Cycles," Econometrica 80: 2733-2764.

Smets, F. and Wouters, R. 2003. "An Estimated Dynamic Stochastic General Equilibrium Model of the Euro Area," Journal of the European Economic Association, 1: $1123-1175$.

Smets, F. and Wouters, R. 2007. "Shocks and Frictions in US Business Cycles: A Bayesian DSGE Approach," American Economic Review, 97(3): 586-606. 
Strassner, E. H. and Moyer, B. C. 2002. "An Analysis of the Composition of Intermediate Inputs by Industry," BEA Working Paper No. 2002-05.

Woodford, M. 2003. Interest and Prices, Princeton, New Jersey: Princeton University Press. 


\section{Appendix}

The rest of the model is the same as that in the SW model. The Consumption Euler equation is given by:

$c_{t}=-\frac{1-\frac{h}{\gamma}}{\sigma_{c}\left(1+\frac{h}{\gamma}\right)}\left(R_{t}-E_{t} \pi_{t+1}+b_{t}\right)+\frac{\frac{h}{\gamma}}{1+\frac{h}{\gamma}} c_{t-1}+\frac{1}{1+\frac{h}{\gamma}} E_{t} c_{t+1}+\frac{\sigma_{c}-1}{\sigma_{c}\left(1+\frac{h}{\gamma}\right)} \frac{w_{*}^{h} L_{*}}{c_{*}}\left(L_{t}-E_{t} L_{t+1}\right)$

where $c_{t}$ is consumption, $L_{t}$ is labour supply, $R_{t}$ is nominal riskless interest rate, and $\pi_{t}$ is inflation. $b_{t}$ is an exogenous shock such that a positive shock increases the required return on assets and increases the cost of capital and reduces the value of capital and investment. $b_{t}$ follows an $\operatorname{AR}(1)$ process with parameters $\rho_{b}$ and $\sigma_{b} . h$ is the habit persistence parameter which makes consumption more persistent for higher values of $h$ and vice versa. Finally, $\sigma_{c}$ is the relative risk aversion parameter. The consumption process is derived from non-separable utility in labour and consumption. Variables with $*$ are the respective steady states.

The resource constraint is given by (29) with $g_{t}$ as the exogenous government spending:

$$
y_{t}=\frac{c_{*}}{y_{*}} c_{t}+\frac{i_{*}}{y_{*}} i_{t}+\frac{r_{*}^{k} k_{*}}{y_{*}} u_{t}+g_{t}
$$

Exogenous government spending is also affected by the productivity shock such that:

$$
g_{t}=\rho_{g} g_{t-1}+\epsilon_{t}^{g}+\rho_{g a} \epsilon_{t}^{a}
$$

Investment Euler equation is derived from the capital producers' optimization decision:

$$
i_{t}=\frac{1}{1+\beta \gamma^{1-\sigma_{c}}} i_{t-1}+\frac{\beta \gamma^{1-\sigma_{c}}}{1+\beta \gamma^{1-\sigma_{c}}} E_{t} i_{t+1}+\frac{1}{\left(1+\beta \gamma^{1-\sigma_{c}}\right) S^{\prime \prime} \gamma^{2}} q_{t}^{k}+\mu_{t}
$$


where $\mu_{t}$ is the investment specific technology shock with parameters $\rho_{\mu}$ and $\sigma_{\mu}$ and is also called marginal efficiency of investment shock. $\beta$ is the discount factor for the households. $S^{\prime \prime}$ is the steady state elasticity of the capital adjustment cost function such that a higher value for it reduces the sensitivity of $i_{t}$ to the real value of existing capital stock, $q_{t}^{k}$.

Existing capital stock itself evolves according to:

$$
\bar{k}_{t}=\left(1-\frac{i_{*}}{\bar{k}_{*}}\right) \bar{k}_{t-1}+\frac{i_{*}}{\bar{k}_{*}} i_{t}+\left(1+\beta \gamma^{1-\sigma_{c}}\right) S^{\prime \prime} \gamma^{2} \frac{i_{*}}{\bar{k}_{*}} \mu_{t}
$$

where $\bar{k}_{t}$ is the installed capital stock and $\frac{i_{*}}{k_{*}}$ is the steady state ratio of investment to installed capital. Since there is a lag in the capital installation, capital services are a function of previously installed capital and the capital utilization decision taken by the entrepreneurs after observing the risk shock:

$$
k_{t}=\bar{k}_{t-1}+u_{t}
$$

where capital utilization, $u_{t}$, is a function of the rental rate of capital:

$$
u_{t}=\frac{1-\varphi}{\varphi} r_{t}^{k}
$$

such that a higher value for $\varphi(\in 0,1)$ reflects high adjustment costs in terms of consumption goods. Rental rate of capital,$r_{t}^{k}$, is assumed to be identical across the two sectors:

$$
r_{t}^{k}=-\left(k_{t}^{i}-L_{t}^{i}\right)+w_{t}
$$

where $i=s, m$ represent the finished goods and intermediate sector, respectively. 
Wages, $w_{t}$, are determined by the wage Phillips curves:

$$
\begin{aligned}
w_{t}= & \frac{\left(1-\zeta_{w} \beta \gamma^{1-\sigma_{c}}\right)\left(1-\zeta_{w}\right)}{\left(1+\beta \gamma^{1-\sigma_{c}}\right) \zeta_{w}\left(\left(\lambda_{w}-1\right) \epsilon_{w}+1\right)}\left(w_{t}^{h}-w_{t}\right)-\frac{1+\iota_{w} \beta \gamma^{1-\sigma_{c}}}{1+\beta \gamma^{1-\sigma_{c}}} \pi_{t}+ \\
& \frac{1}{1+\beta \gamma^{1-\sigma_{c}}}\left(w_{t-1}-\iota_{w} \pi_{t-1}\right)+\frac{\beta \gamma^{1-\sigma_{c}}}{1+\beta \gamma^{1-\sigma_{c}}} \mathbb{E}_{t}\left[w_{t+1}+\pi_{t+1}\right]+\lambda_{w, t}
\end{aligned}
$$

where $\zeta_{w}, \iota_{w}$ and $\epsilon_{w}$ are the Calvo parameter for wage stickiness, degree of indexation and the curvature parameter in the Kimball aggregator for wages, respectively. $\lambda_{w, t}$ is the wage markup shock following an $\operatorname{ARMA}(1,1)$ process similar to SW with parameters $\rho_{w}, \sigma_{w}$ and $\mu_{w} . w_{t}^{h}$ is the household's marginal rate of substitution between consumption and labor:

$$
w_{t}^{h}=\frac{1}{1-\frac{h}{\gamma}}\left(c_{t}-\frac{h}{\gamma} c_{t-1}\right)+\sigma_{l} L_{t}
$$

The model is closed with the central bank following a feedback rule of the type in equation (37). The central bank adjusts the nominal short-term interest rate in response to its lagged value, inflation and change in the inflation gap, in addition to output gap and change in the output gap:

$$
R_{t}=\rho_{R} R_{t-1}+\left(1-\rho_{R}\right)\left[r_{\pi}\left(\pi_{t}-\pi_{t}^{*}\right)+r_{y}\left(y_{t}-y_{t}^{*}\right)\right]+r_{\triangle y}\left[\left(y_{t}-y_{t}^{*}\right)-\left(y_{t-1}-y_{t-1}^{*}\right)\right]+m_{t}^{r}
$$

where $y_{t}^{*}$ is the flexible level of output. $\pi_{t}^{*}$ is the target level of inflation which evolves according to an $\mathrm{AR}(1)$ proces with parameters $\rho_{\pi^{*}}$ and $\sigma_{\pi^{*}}$. The monetary policy shock, $m_{t}^{r}$, also follows an $\operatorname{AR}(1)$ process with parameters $\rho_{r}$ and $\sigma_{r}$. 
Table 4: Prior and Posterior Estimates of Structural Parameters

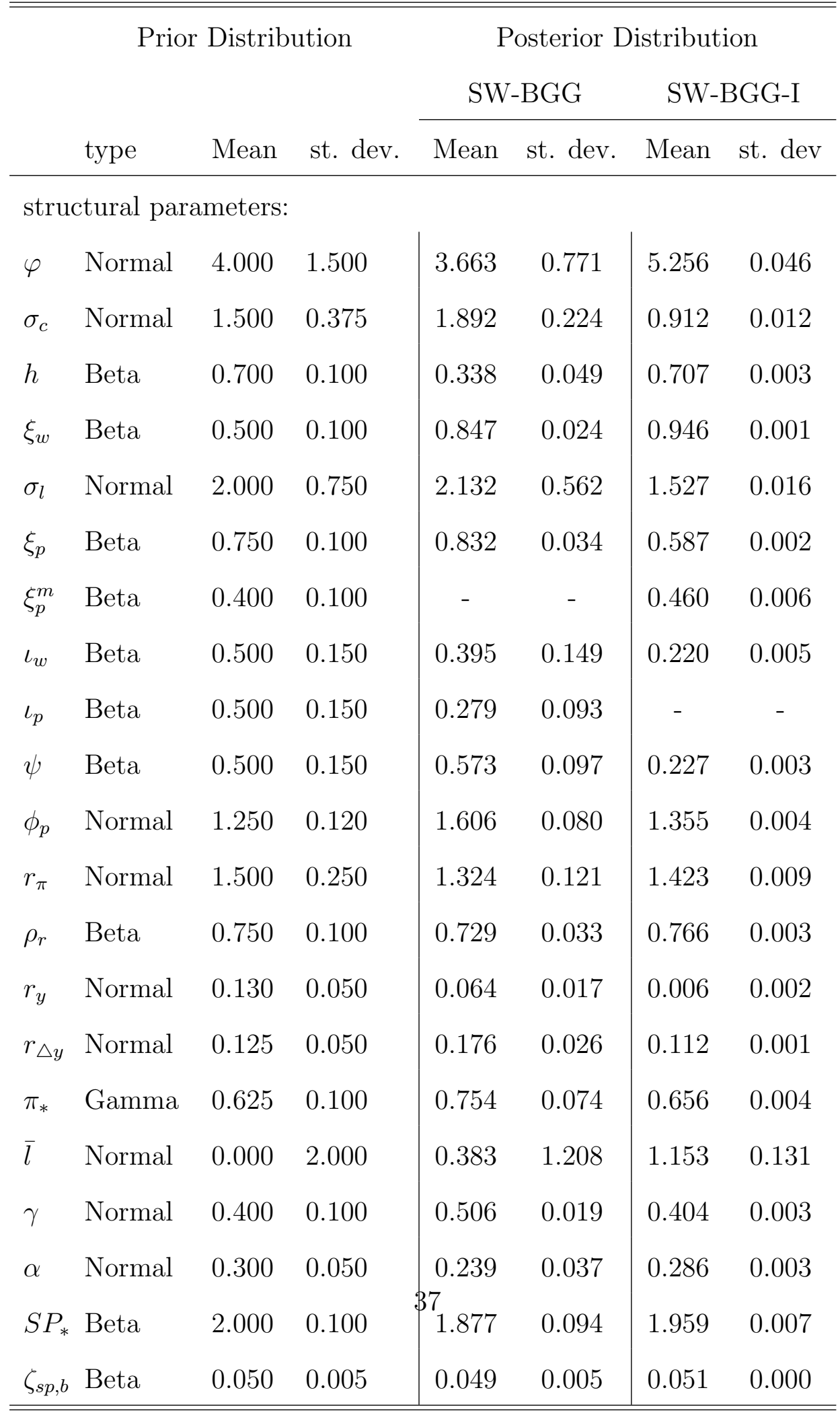


Table 5: Prior and Posterior Estimates of Shock Processes

\begin{tabular}{|c|c|c|c|c|c|c|c|}
\hline & \multicolumn{3}{|c|}{ Prior Distribution } & \multicolumn{4}{|c|}{ Posterior Distribution } \\
\hline & \multirow[b]{2}{*}{ type } & \multirow[b]{2}{*}{ Mean } & \multirow[b]{2}{*}{ st. dev. } & \multicolumn{2}{|c|}{ SW-BGG } & \multicolumn{2}{|c|}{ SW-BGG-I } \\
\hline & & & & Mean & st. dev. & Mean & st. dev \\
\hline \multicolumn{8}{|c|}{ persistence of exogenous shocks: } \\
\hline$\rho_{a}$ & Beta & 0.500 & 0.200 & 0.915 & 0.017 & 0.995 & 0.002 \\
\hline$\rho_{a^{f}}$ & Beta & 0.500 & 0.200 & - & - & 0.616 & 0.002 \\
\hline$\rho_{e i}$ & Beta & 0.500 & 0.200 & - & - & 0.165 & 0.007 \\
\hline$\rho_{e i^{1}}$ & Beta & 0.500 & 0.200 & - & - & 0.012 & 0.001 \\
\hline$\rho_{\bar{\sigma}}$ & Beta & 0.750 & 0.150 & 0.984 & 0.005 & 0.987 & 0.002 \\
\hline$\rho_{b}$ & Beta & 0.500 & 0.200 & 0.994 & 0.003 & 0.996 & 0.001 \\
\hline$\rho_{g}$ & Beta & 0.500 & 0.200 & 0.987 & 0.005 & 0.986 & 0.004 \\
\hline$\rho_{\mu}$ & Beta & 0.500 & 0.200 & 0.998 & 0.000 & 0.998 & 0.002 \\
\hline$\rho_{r}$ & Beta & 0.500 & 0.200 & 0.104 & 0.049 & 0.206 & 0.012 \\
\hline$\rho_{\pi}$ & Beta & 0.500 & 0.200 & 0.808 & 0.049 & - & - \\
\hline$\rho_{\pi^{*}}$ & Beta & 0.500 & 0.200 & 0.902 & 0.014 & 0.899 & 0.008 \\
\hline$\rho_{w}$ & Beta & 0.500 & 0.200 & 0.575 & 0.173 & 0.499 & 0.007 \\
\hline$\mu_{p}$ & Beta & 0.500 & 0.200 & 0.728 & 0.074 & - & - \\
\hline$\mu_{w}$ & Beta & 0.500 & 0.200 & 0.469 & 0.203 & 0.771 & 0.005 \\
\hline$\rho_{g a}$ & Normal & 0.500 & 0.250 & 0.452 & 0.116 & 0.398 & 0.006 \\
\hline$\rho_{\bar{\sigma}, n}$ & Inv.Gamma & 1.000 & 2.000 & 0.729 & 0.053 & 0.664 & 0.039 \\
\hline$\sigma_{a}$ & Inv.Gamma & 0.100 & 2.000 & 0.368 & 0.025 & 0.570 & 0.038 \\
\hline$\sigma_{a^{f}}$ & Inv.Gamma & 1.000 & 2.000 & - & - & 1.473 & 0.064 \\
\hline$\sigma_{e i}$ & Inv.Gamma & 0.100 & 2.000 & - & - & 0.969 & 0.059 \\
\hline$\sigma_{\bar{\sigma}}$ & Inv.Gamma & 0.050 & 4.000 & 0.052 & 0.005 & 0.054 & 0.005 \\
\hline$\sigma_{b}$ & Inv.Gamma & 0.100 & 2.000 & 0.029 & 0.004 & 0.027 & 0.002 \\
\hline$\sigma_{g}$ & Inv.Gamma & 0.010 & 2.000 & 0.438 & 0.030 & 0.543 & 0.041 \\
\hline$\sigma_{\mu}$ & Inv.Gamma & 0.100 & 2.000 & 0.372 & 0.073 & 0.249 & 0.020 \\
\hline$\sigma_{r}$ & Inv.Gamma & 0.100 & $2.000 \quad 38$ & 0.194 & 0.015 & 0.222 & 0.015 \\
\hline$\sigma_{\pi}$ & Inv.Gamma & 0.100 & 2.000 & 0.114 & 0.011 & - & - \\
\hline$\sigma_{\pi^{*}}$ & Inv.Gamma & 0.100 & 2.000 & 0.176 & 0.036 & 0.163 & 0.022 \\
\hline$\sigma_{w}$ & Inv.Gamma & 0.100 & 2.000 & 0.315 & 0.036 & 0.476 & 0.030 \\
\hline
\end{tabular}


Figure 1: Evolution of Actual Energy and Intermediate Prices

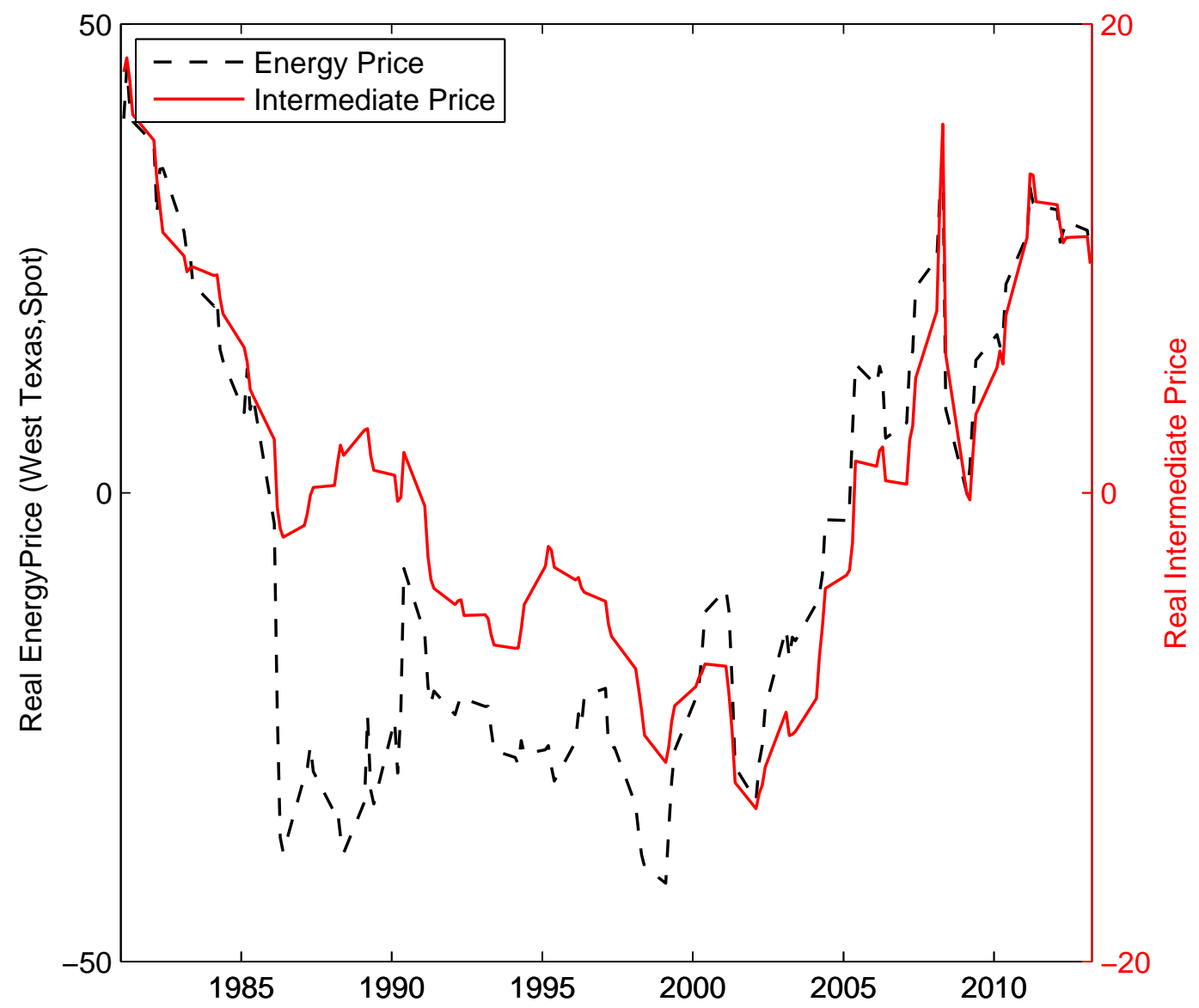

Note: The dashed black line is the log of deflated Energy Prices. The solid red line is the log of deflated intermediate prices. Both the data series are seasonally adjusted and are obtained from the St. Louis FED database. We deflate the two series using the GDP deflator. The intermediate price series is the Producer Price Index by Commodity Intermediate Materials: Supplies \& Components (PPIITM). The energy price series is the Producer Price Index: Finished Energy Goods (PPIFEG). 
Figure 2: Marginal Cost with and without Intermediate Sector

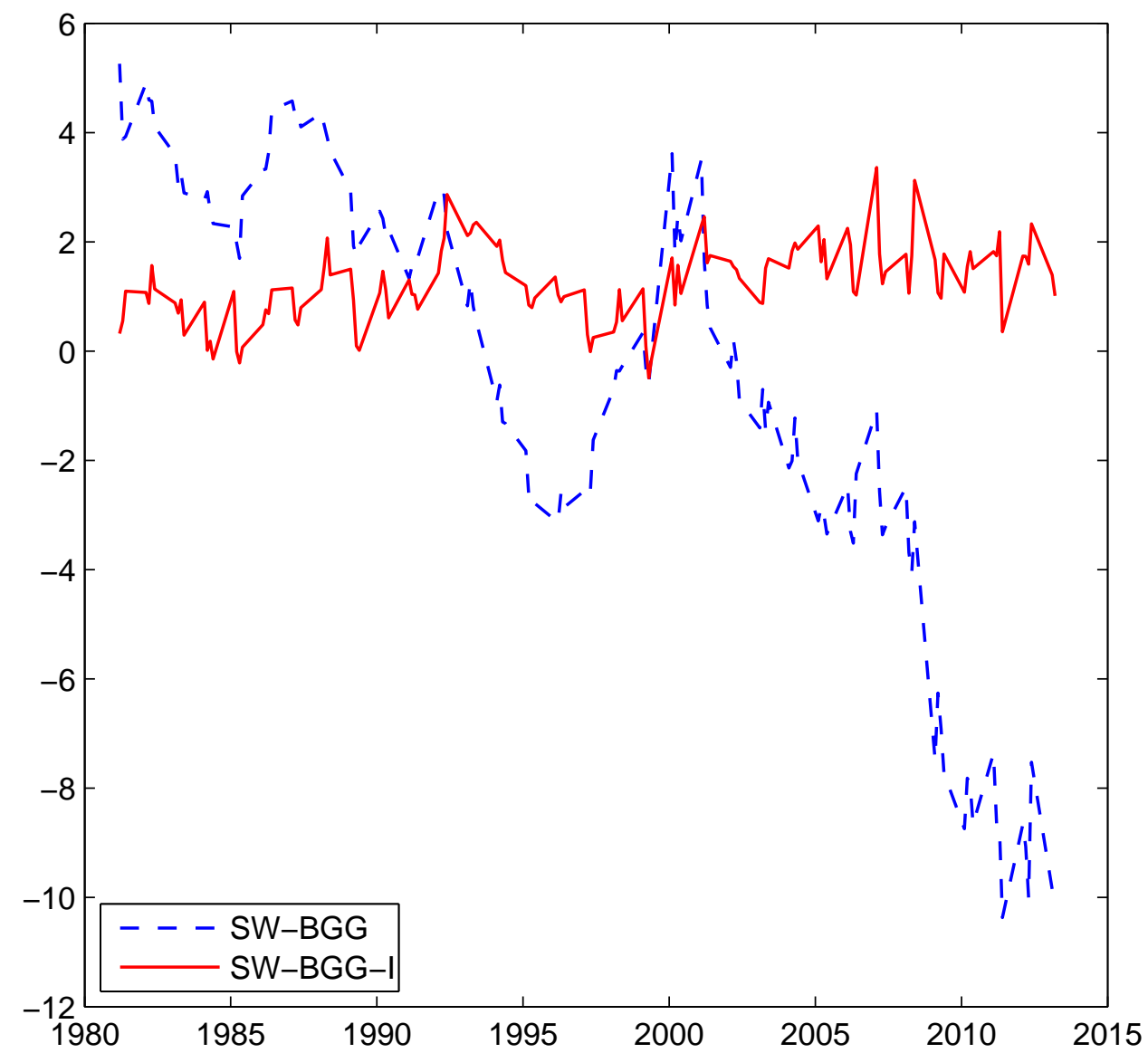

Note: The dashed blue line is the smoothed marginal cost, $E\left[m c_{t} \mid Y_{1: T_{\text {full }}}\right]$, from the SWBGG. The solid red line is the smoothed marginal cost from the SW-BGG-I. 
Figure 3: Forecasts of Inflation and Output Growth
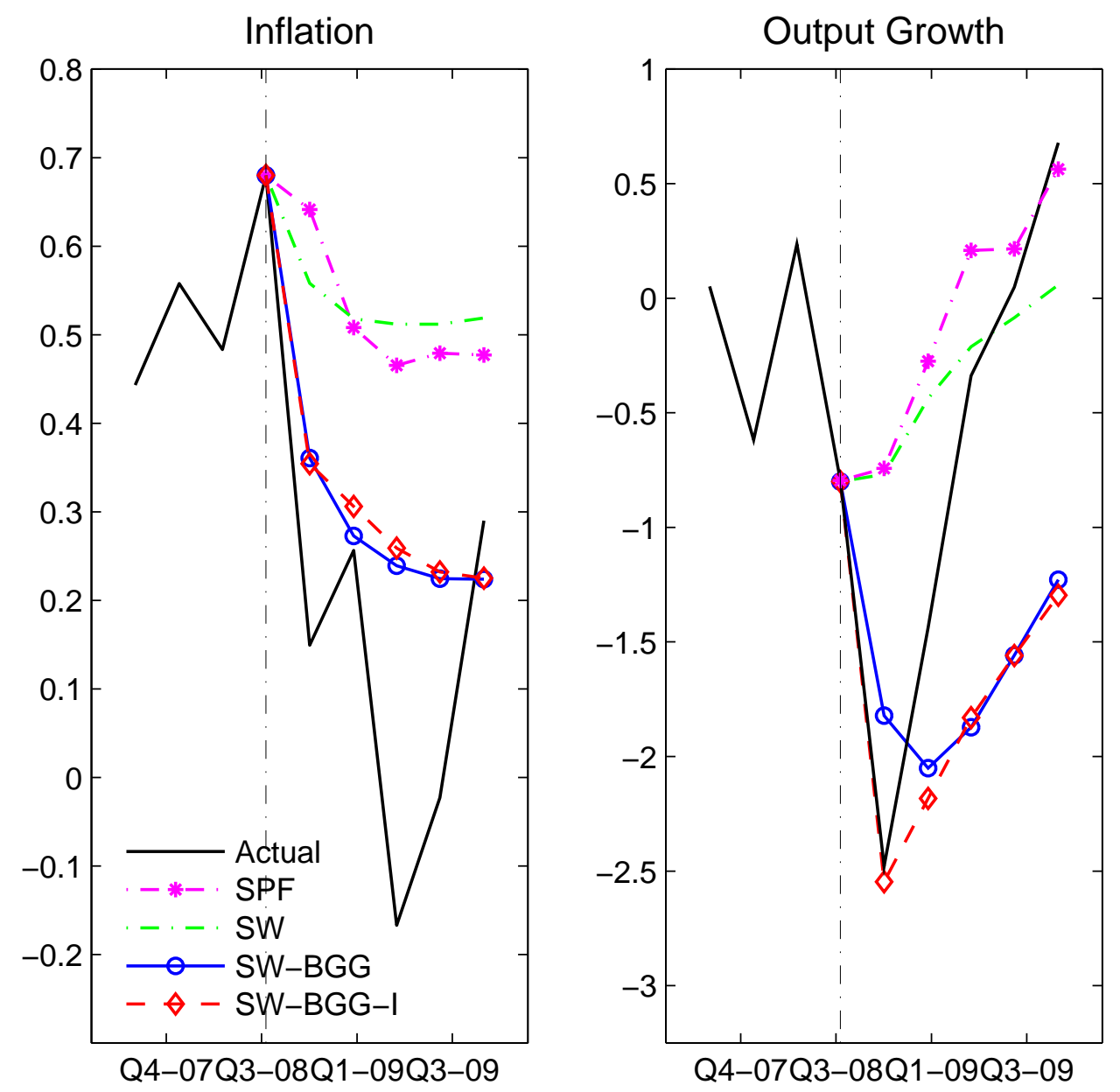

Note: The solid black line in the two panels is the data for inflation and output growth, respectively. Dashed red line with diamonds is the forecast from SW-BGG-I whereas the solid blue line with circiles is the forecast from SW-BGG. Dashed green line plots the SW forecast. Forecast from SPF is shown with the star-dotted-dashed magenta line. 
Figure 4: Inflation Forecast under Similar Price Rigidities
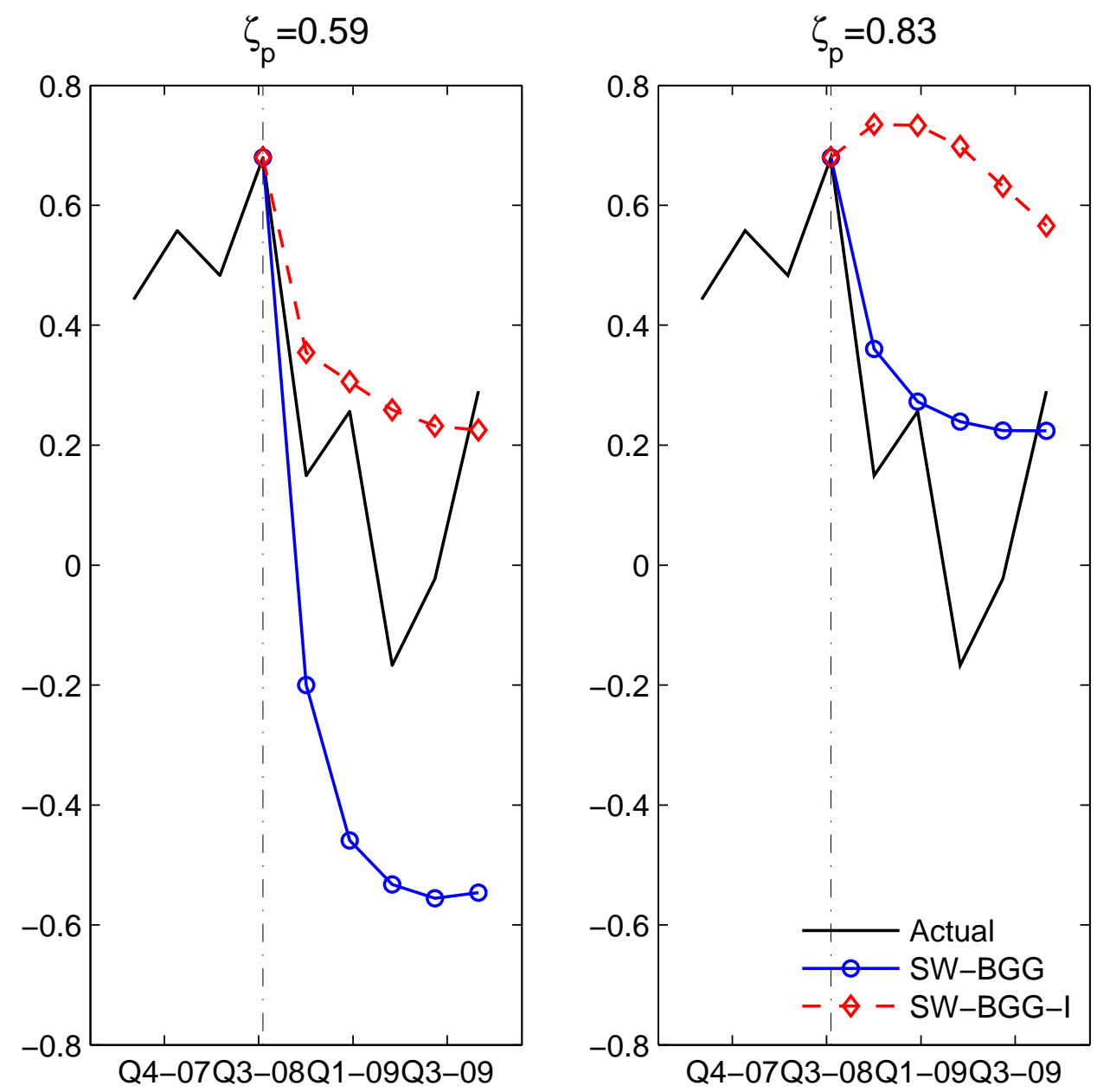

Note: The solid black line in the two panels is the data for inflation. Dashed red line with diamonds is the forecast from SW-BGG-I whereas the solid blue line with circiles is the forecast from SW-BGG. 
Figure 5: Forecasts of Output Growth without the Anticipated Component of the Risk shock

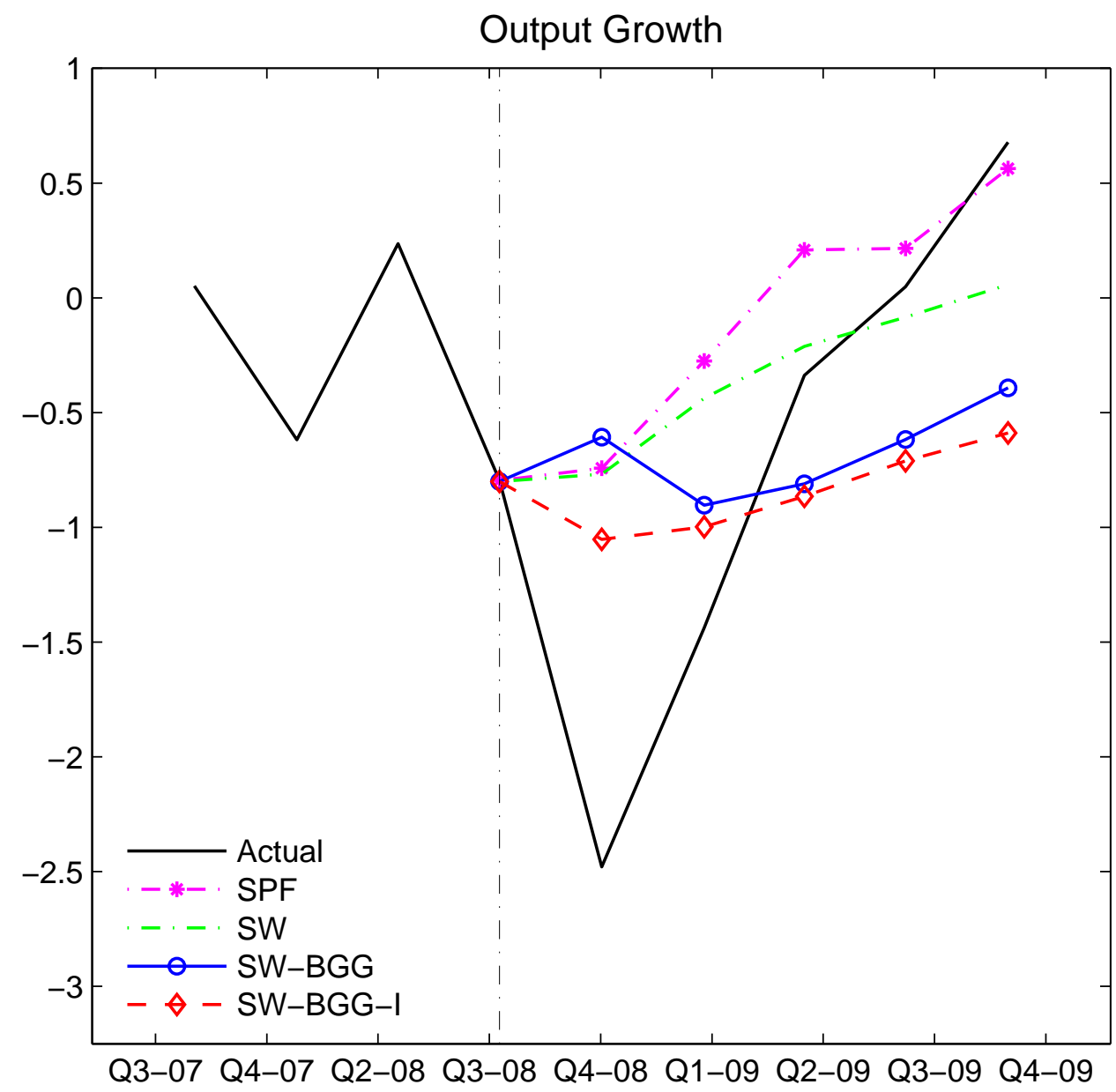

Note: The solid black line in the two panels is the data for inflation and output growth, respectively. Dashed red line with diamonds is the forecast from SW-BGG-I whereas the solid blue line with circiles is the forecast from SW-BGG. Dashed green line plots the SW forecast. Forecast from SPF is shown with the star-dotted-dashed magenta line. 


\section{Figure 6: Forecasts of the Federal Funds Rate}

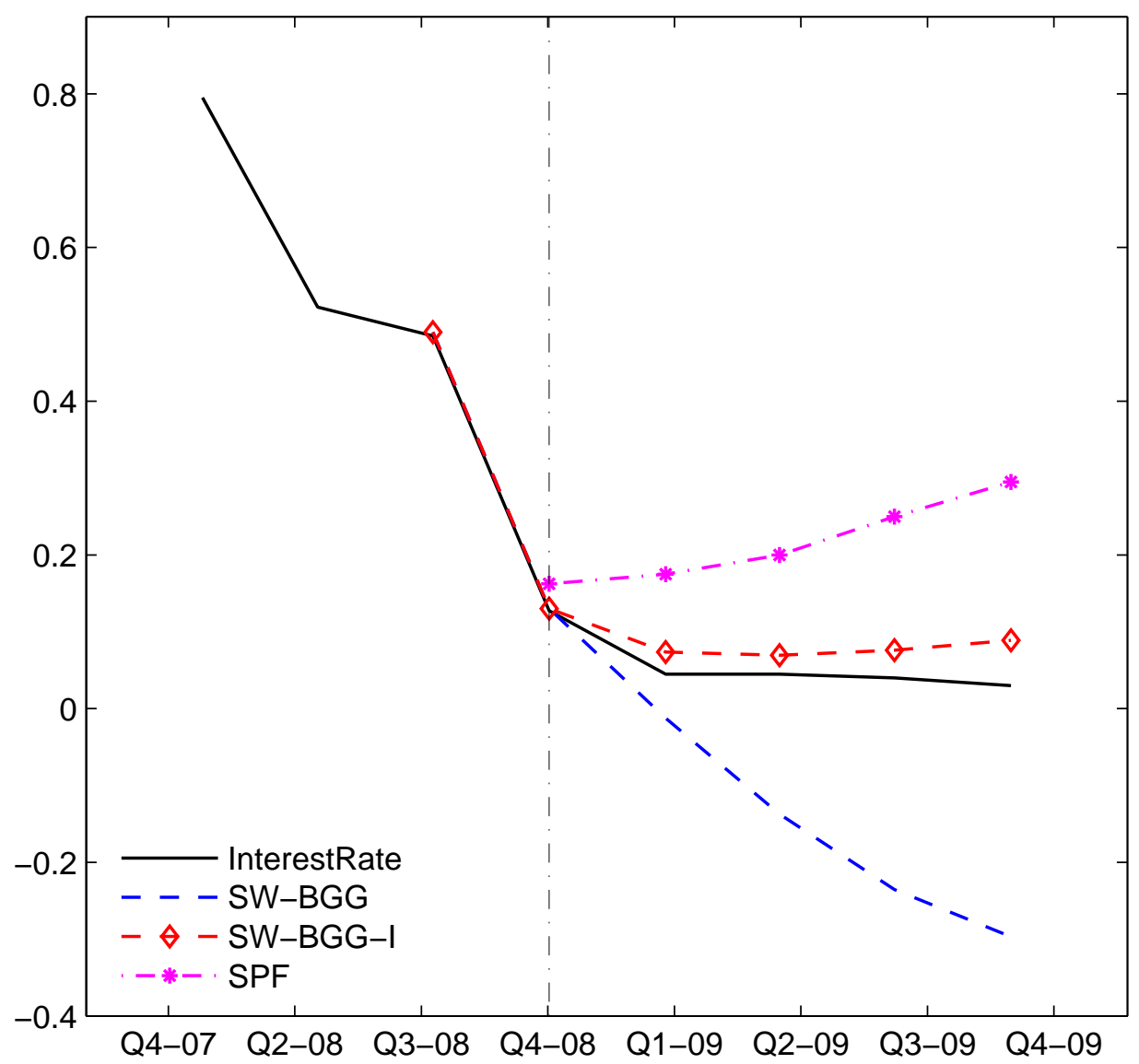

Note: Since model forecasts are conditional on Quarter 4, 2008 interest rate and spread data, the first forecast period for interest rate is Quarter1, 2009. The solid black line is the data for Federal Funds Rate. Dashed red line with diamonds is the forecast from SWBGG-I whereas dashed blue line is the forecast from SW-BGG. The star-dotted-dashed line of magenta color is the SPF forecast. 
Figure 7: Marginal Cost and its Forecast

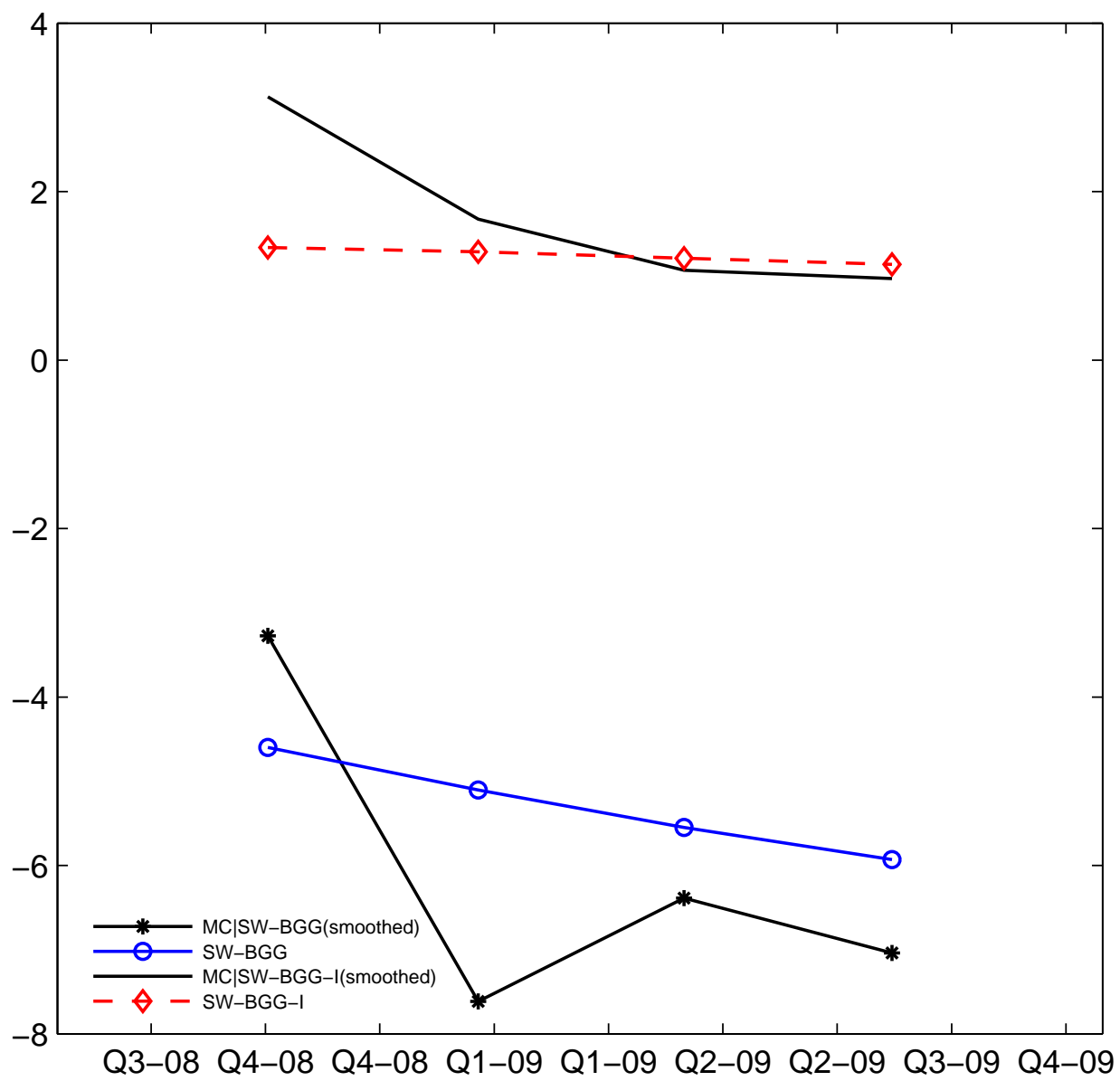

Note: The solid black line is the smoothed marginal cost, $E\left[m c_{t} \mid Y_{1: T_{f u l l}}\right]$, from the SWBGG-I. The solid-star black line is the smoothed marginal cost from the SW-BGG. The colored lines show the forecasts where dashed red line with diamonds is the forecast from SW-BGG-I and the solid blue line with circles is the forecast from SW-BGG. 
Figure 8: Impulse Responses to Intermediate Input and Price Markup shocks
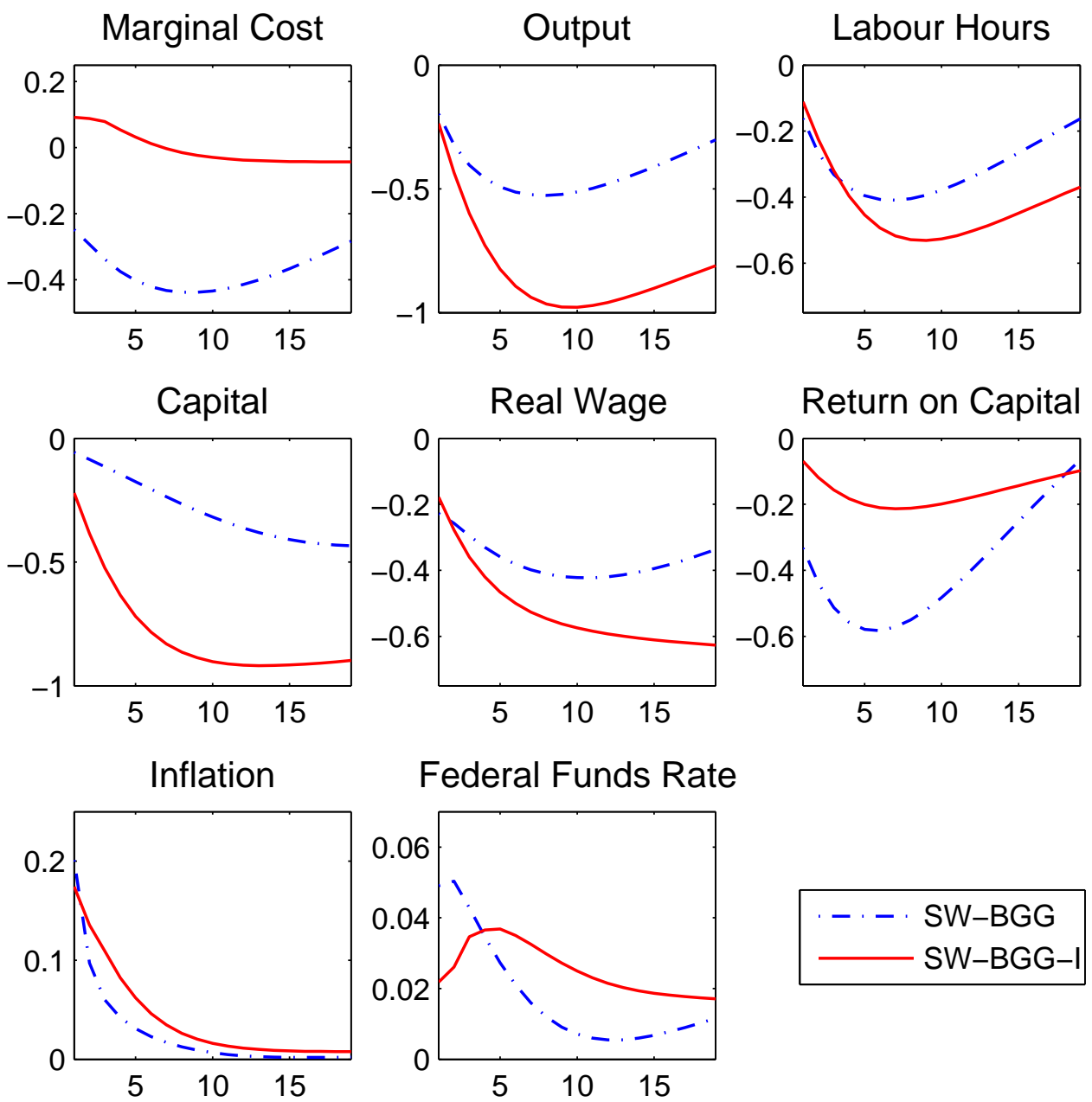

Federal Funds Rate
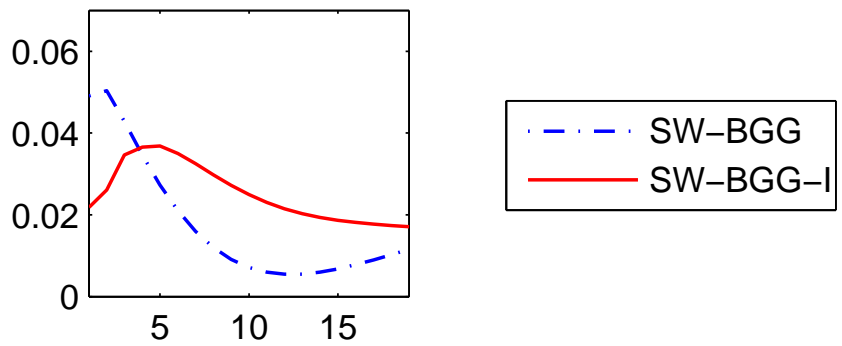

Note: The dashed black blue line is the IRF to the price markup shock in SW-BGG. The solid red line is the IRF to the intermediate input shock in SW-BGG-I. 